\title{
An overview of endothelial dysfunction in diabetes
}

\author{
Haiju H Chirayath* \\ Consultant Endocrinologist, Medcare Hospital, Dubai, United Arab Emirates
}

The endothelium is a single layer of cells constituting the innermost surface of the wall of a vessel. It forms the interface between blood flow and the blood vessel wall. Previously thought to be an inert layer of cells, it is now known to regulate vasomotor tone, by secreting various vasoactive factors which modulate both relaxation and constriction. The endothelium also maintains the anticoagulant, antiplatelet, and fibrinolytic properties of vascular cells. In response to physical and chemical signals, the healthy endothelium produces a wide range of factors that regulate vascular tone, cellular adhesion, thromboresistance, smooth muscle cell proliferation, and vessel wall inflammation [1]. The interest in endothelial function is based on its pivotal role in various diseases such as diabetes, coronary artery disease, cerebro-vascular diseaseand hypertension. Research into endothelial function may pave the way for novel therapies aimed at alleviating the morbidity and mortality from these conditions. Furthermore, as endothelial dysfunction is a common underlying feature of these interrelated disorders, it may be possible to apply knowledge gained by studying one disease to anotherdisease process.

The endothelium secretes a number of mediators involved in vasodilation, the main ones being nitric oxide $(\mathrm{NO})$, prostacyclin (PGI2) and the endothelium derived hyperpolarizing factor (EDHF). $\mathrm{NO}$ is a crucial vasodilator which exerts an anti-aggregatory effect and also limits vascular smooth muscle cell growth and migration. Under certain conditions, the endothelium also produces endotheliumderived vasoconstrictors such as endothelin, prostaglandin $\mathrm{H} 2$ and thromboxane A2, which activate specific receptors on the vascular smooth muscle [2].

\section{Mechanisms of hyperglycemia-induced endothelial dysfunction}

Key processes responsible for hyperglycemia-induced endothelial dysfunction include the polyol pathway, reactive oxygen species (ROS) production, and advanced glycation endproducts (AGEs) formation [3]. One of the reasons endothelial cells are more susceptible to the effects of hyperglycaemia is because of their high expression of the insulin-independent protein that facilitates glucose transport(glucose transporter type 1 or GLUT-1), and the fact that they cannot regulate the glucose uptake through insulin action. This probably makes the endothelial cell more vulnerable to the deleterious effects of hyperglycemia than the smooth muscle cells, which can down-regulate GLUT-1 in response to increasing glucose concentrations [4].

The excess glucose in endothelial cells enters the polyol pathway causing the accumulation of the electron donors like reduced Nicotinamide Adenine Dinucleotide (NADH) and Flavin Adenine Dinucleotide (FADH2) in the mitochondria. This affects the electron transport chain with the excess electrons increasing ROS in mitochondria. ROS in turn trigger accumulation of AGEs and this process results in mitochondrial DNA damage and mitochondrial dysfunction[5]. Protein kinase $\mathrm{C}$ (PKC) and AGE mediated activation of nuclear factor kappa B (NFkB) lead to the expression of inflammation proteins, tumor suppressor $\mathrm{p} 53$, and inducible nitric oxide synthase (iNOS). The latter enzyme leads to increased NO production. NO is highly reactive with superoxide anions and the peroxynitrite generated acts as a strong oxidant. A vicious cycle is thereby set in motion where increasing ROS production increases oxidative stress [6]. In addition to the injury mechanisms, the impairment of protective factors in diabetes also plays a role in endothelial dysfunction. These include resistance to insulin, decrease of endogenous antioxidant enzymes, and dysfunction of endothelial progenitor cells [3]. Endothelial progenitor cells (EPCs) are circulating cells thought to originate from bone marrow, that follow chemokine signaling to reach sites that require neovascularization and vascular repair [7]. EPC number and function have been shown to be significantly diminished in diabetic patients, with reduced levels of up to $50 \%$ in diabetic patients compared to healthy controls [8]. Furthermore, EPCs were found to negatively correlate with disease severity [9].

Hyperglycemia-induced oxidative stress in endothelial cells has also been reported to upregulate plasminogen activator inhibitor 1 (PAI1), which prevents fibrinolysis [10] in addition to down regulating the platelet inhibitor prostacyclin [11]. These events collectively increase the adhesion of macrophages and platelets to the endothelium, which in turn increase the risk for ischemic heart disease and cerebro-vascular disease in addition to other vascular diseases in diabetes. Current knowledge suggests that endothelial injury and dysfunction occur as the initial event in the pathogenesis of atherosclerosis, followed by platelet adhesion and aggregation [12].

Impaired endothelium-dependent vasodilation has been demonstrated in various vascular beds such as forearm, cerebral, coronary and subcutaneous arteries in patients with diabetes as well as various animal models of this disease. Impaired endothelial cell selfrenewal with reduced turnover potential has been noted in the retinal microvasulature of diabetic rats [13]. This leads to hypoxia, which upregulates vascular endothelial growth factor (VEGF), contributing to elevated vascular permeability [14]. This can result in diabetic macular edema progressing to possible loss of visual function [15].

The discovery of endothelial microparticles (EMPs) revealed another factor contributing to endothelial dysfunction. EMPs are

Correspondence to: Haiju $\mathrm{H}$ Chirayath, $\mathrm{PhD}, \mathrm{MSc}, \mathrm{MRCP}(\mathrm{UK})$, Consultant Endocrinologist, Medcare Hospital, Dubai, United Arab Emirates, E-mail: haiju. chirayath@gmail.com

Key words: diabetes, endothelial dysfunction, endothelium

Received: November 05, 2016; Accepted: November 21, 2016; Published: November 24, 2016 
membrane vesicles derived from activated or apoptotic endothelial cells. The plasma level of EMPs is significantly elevated in diabetic patients compared to age-matched healthy controls [16], with levels being higher in diabetic patients with vascular complications [17]. Studies have demonstrated that EMPs contribute to coagulation [18], disruption of angiogenesis [19], and cerebral capillary damage [20], in addition to other vascular effects such as inflammation [21]. These EMPs may have pathogenic effects in vascular thrombosis and angiogenesis [22], which are essential for the development of DM and its complications.

Endothelial dysfunction is closely associated with insulin resistance, which is a common feature of diabetes, obesity, hypertension, and coronary artery disease. It refers to the state of decreased insulin response [23] and is associated with glucotoxicity, lipotoxicity, and inflammation, which initiates and accelerates atherogenesis and vascular disease [24]. The molecular mechanisms of insulin resistance have been delineated and impairment of the PI3-K/Akt signalling pathway has been noted, which leads to an inadequate tissue insulin sensitivity.This in turn leads to compensatory hyperinsulinaemia, which contributes to diminished activity of the PI3-K/Akt pathway and enhancement of the MAPK/ERK pathway [25]. The differences in activity of both pathways lead to various effects of insulin resistance in different organs,such as the lack of suppression of glucose production by insulin and maintained lipogenesis in the liver [26] or decreased production of nitric oxide and enhanced production of ET-1 in endothelium [27].

\section{Improving endothelial function in diabetes}

The management of diabetes previously revolved around normalizing blood glucose levels, but as we learn more and more about this disease, the importance of maintaining optimum endothelial function is becoming clearer. Indeed, it is possible that future management of diabetes may include therapies focusing purely on improving endothelial function rather than solely lowering blood glucose levels. This paradigm shift may help in reducing the various vascular complications of diabetes including ischemic heart disease and cerebro-vascular disease.

The options for improving endothelial function in diabetes involve both lifestyle factors and medications. Some of the lifestyle modifications known to improve diabetes control such as reducing food intake and exercise have also been demonstrated to enhance endothelial function. Decreasing caloric intake has been shown to trigger endothelial AMPK-PI3K-Akt-eNOS activation leading to normalization of endothelial function and systolic BP reduction in Zucker obese rats [28]. Caloric restriction also improved vascular compliance [29] and revascularization in response to ischemia [30].

The type of food consumed has been shown to affect endothelial function. A diet high in polyunsaturated fatty acids (Mediterranean diet) was shown to increase EPC and reduce oxidative stress $[31,32]$. Exercise has been demonstrated to increase the number of EPC and improve their migratory capacity, thereby helping to repair damaged endothelium $[32,33]$.

Various medications that are currently in use for managing diabetes have also been shown to improve endothelial function. The first-line drug in the management of Type 2 diabetes is Metformin and this drug is believed to enhance endothelial function through AMP-activated protein kinase (AMPK), which leads to phosphorylation of eNOS, thereby stimulating the release of the endothelium-derived vasodilator
NO [34]. The key drug insulin exerts its pharmacological effect on the endothelium by activating the insulin receptor on endothelial cells, which leads to PI3K-/PKB-dependent phosphorylation of eNOS and stimulation of NO production [35]. The glucagon-like peptide -1 (GLP-1) receptor agonist Exendin-4 (from which Exenatide is derived), has been shown to increase NO production, stimulate proliferation and protect from lipid-induced apoptosis of human coronary artery endothelial cells, throughPI3K/protein kinase $\mathrm{B}$, protein kinase A and eNOS-dependent pathways [36]. Other existing drugs used in diabetes management that have effects on endothelial function include statins, phosphodiesterase- 5 inhibitors, calcium channel blockers, beta blockers and ACE inhibitors [37].

In the future, EPCs may potentially be used for therapeutic purposes to aid regeneration of ischemic tissues; due to their ability to migrate to remote areas and promote new blood vessel formation in regions with vascular insufficiency [38]. Various strategies are being investigated to reverse EPC dysfunction caused by diabetes including enhancement of angiogenic stimulus using G-CSF (granulocytemacrophage colony-stimulating factor) [39] and usage of nitric oxide donor to reverse stromal cell-derived factor 1 (SDF-1) mediated migration defects [40]. These strategies may potentially lead to novel treatments which normalize impaired endothelial function by regenerating damaged endothelial cells. Other new treatment options for improving endothelial function are also being researched currently. These include the eNOS transcription enhancer AVE3085, Ivabradine and Sphingosine-1-phosphate amongst others [41-43].

In summary, endothelial dysfunction associated with diabetes is one of the important causes for the morbidity and mortality associated with this disease. Understanding the pathogenesis and molecular pathways of endothelial will help formulate novel therapeutic options in the future. With the dramatically rising prevalence of diabetes worldwide, it is hoped that this knowledge will help minimize the complications of diabetes and attenuate its future impact on global health.

\section{References}

1. Rajendran P, Rengarajan T, Thangavel J, Nishigaki Y, Sakthisekaran D, et al. (2013) The vascular endothelium and human diseases. Int J Biol Sci 9: 1057-1069. [Crossref]

2. Guerci B, Kearney-Schwartz A, Bohme P, Zannad F, Drouin P (2001) Endothelial dysfunction and type 2 diabetes. Part 1: physiology and methods for exploring the endothelial function. Diabetes Metab 27: 425-434. [Crossref]

3. Rajasekar P, O'Neill CL, Eeles L, Stitt AW, Medina RJ (2015) Epigenetic changes in endothelial progenitors as a possible cellular basis for glycemic memory in diabetic vascular complications. J Diabetes Res.

4. Kaiser N, Sasson S, Feener EP, Boukobza-Vardi N, Higashi S, et al. (1993) Differential regulation of glucose transport and transporters by glucose in vascular endothelial and smooth muscle cells. Diabetes 42: 80-89. [Crossref]

5. Madsen-Bouterse SA, Zhong Q, Mohammad G, Ho YS, Kowluru RA (2010) Oxidative damage of mitochondrial DNA in diabetes and its protection by manganese superoxide dismutase. Free Radic Res 44: 313-321. [Crossref]

6. Ihnat MA, Thorpe JE, Kamat CD, Szabó C, Green DE, et al. (2007) Reactive oxygen species mediate a cellular 'memory' of high glucose stress signalling. Diabetologia 50: 1523-1531. [Crossref]

7. Rafii S, Lyden D (2003) Therapeutic stem and progenitor cell transplantation for organ vascularization and regeneration. Nature Medicine 9: 702-712. [Crossref]

8. Loomans CJ, de Koning EJ, Staal FJ, Rookmaaker MB, Verseyden C, et al. (2004) Endothelial progenitor cell dysfunction-a novel concept in the pathogenesis of vascular complications of type 1 diabetes. Diabetes 53: 195-199. [Crossref]

9. Egan CG, Lavery R, Caporali F, Fondelli C, Laghi-Pasini F, et al. (2008) Generalised reduction of putative endothelial progenitors and CXCR4-positive peripheral blood cells in type 2 diabetes. Diabetologia 51: 1296-1305. 
10. Rikitake Y, Liao JK (2005) Rho-kinase mediates hyperglycemia-induced plasminogen activator inhibitor-1 expression in vascular endothelial cells. Circulation 111: 32613268. [Crossref]

11. Umeda F, Ono Y, Masakado M, Sekiguchi N, Yamauchi T, et al. (1996) Prostacyclinstimulating factor, novel protein, and diabetic angiopathy. Diabetes 45: S111-S113. [Crossref]

12. Polovina MM, Potpara TS (2014) Endothelial dysfunction in metabolic and vascular disorders. Postgrad Med 126: 38-53. [Crossref]

13. Sharma NK, Gardiner TA, Archer DB (1985) A morphologic and autoradiographic study of cell death and regeneration in the retinal microvasculature of normal and diabetic rats. Am J Ophthalmol 100: 51-60. [Crossref]

14. Tolentino MJ, McLeod DS, Taomoto M, Otsuji T, Adamis AP, et al. (2002) Pathological features of vascular endothelial growth factor-induced retinopathy in non-human primates. Am J Ophthalmol 133: 373-385. [Crossref]

15. Stitt AW, O'Neill CL, O'Doherty MT, Archer DB, Gardiner TA, et al. (2011) Vascular stem cells and ischaemic retinopathies. Prog Retin Eye Res 30: 149-166. [Crossref]

16. Tramontano AF, Lyubarova R, Tsiakos J, Palaia T, Deleon JR, et al. (2010) Circulating endothelial microparticles in diabetes mellitus. Mediators Inflamm 2010: 250476. [Crossref]

17. Koga H, Sugiyama S, Kugiyama K, Watanabe K, Fukushima H, et al. (2005) Elevated levels of VE-cadherin-positive endothelial microparticles in patients with type 2 diabetes mellitus and coronary artery disease. J Am Coll Cardiol 45: 1622-1630. [Crossref]

18. Sabatier F, Darmon P, Hugel B, Combes V, Sanmarco M, et al. (2002) Type 1 and type 2 diabetic patients display different patterns of cellular microparticles. Diabetes 51: 2840-2845. [Crossref]

19. Bernard S, Loffroy R, Sérusclat A, Boussel L, Bonnefoy E, et al. (2009) Increased levels of endothelial microparticles CD144 (VE-Cadherin) positives in type 2 diabetic patients with coronary noncalcified plaques evaluated by multidetector computed tomography (MDCT). Atherosclerosis 203: 429-435. [Crossref]

20. Chen J, Chen S, Chen Y, Zhang C, Wang J, et al. (2011) Circulating endothelial progenitor cells and cellular membrane microparticles in $\mathrm{db} / \mathrm{db}$ diabetic mouse: possible implications in cerebral ischemic damage. Am J Physiol Endocrinol Metab 301: E62-E71. [Crossref]

21. Markiewicz M, Richard E, Marks N, Ludwicka-Bradley A (2013) Impact of endothelia microparticles on coagulation, inflammation, and angiogenesis in age-related vascular diseases. Journal of Aging Research.

22. Mallat Z, Benamer H, Hugel B, Benessiano J, Steg PG, et al. (2000) Elevated levels of shed membrane microparticles with procoagulant potential in the peripheral circulating blood of patients with acute coronary syndromes. Circulation 101: 841-843. [Crossref]

23. Rask-Madsen C, Kahn CR (2012) Tissue-specific insulin signaling, metabolic syndrome, and cardiovascular disease. Arterioscler Thromb Vasc Biol 32: 2052-2059. [Crossref]

24. Ouchi N, Parker JL, Lugus JJ, Walsh K (2011) Adipokines in inflammation and metabolic disease. Nat Rev Immunol 11: 85-97. [Crossref]

25. Cusi K, Maezono K, Osman A, Pendergrass M, Patti ME, et al. (2000) Insulin resistance differentially affects the PI 3-kinase- and MAP kinase-mediated signaling in human muscle. J Clin Invest 105: 311-320. [Crossref]

26. Brown MS, Goldstein JL (2008) Selective versus total insulin resistance: a pathogenic paradox. Cell Metab 7: 95-96. [Crossref]

27. Muniyappa R, Montagnani M, Koh KK, Quon MJ (2007) Cardiovascular actions of insulin. Endocr Rev 28: 463-491. [Crossref]
28. García-Prieto CF, Pulido-Olmo H, Ruiz-Hurtado G, Gil-Ortega M, Aranguez I, et al. (2015) Mild caloric restriction reduces blood pressure and activates endothelial AMPK-PI3K-Akt-eNOS pathway in obese Zucker rats. Vascul Pharmacol 65-66: 3-12. [Crossref]

29. Dolinsky VW, Morton JS, Oka T, Robillard-Frayne I, Bagdan M, et al. (2010) Calorie restriction prevents hypertension and cardiac hypertrophy in the spontaneously hypertensive rat. Hypertension 56: 412-421. [Crossref]

30. Kondo M, Shibata R, Miura R, Shimano M, Kondo K, et al. (2009) Caloric restriction stimulates revascularization in response to ischemia via adiponectin-mediated activation of endothelial nitric-oxide synthase. J Biol Chem 284: 1718-1724. [Crossref]

31. Turgeon J, Dussault S, Maingrette F, Groleau J, Haddad P, et al. (2013) Fish oil-enriched diet protects against ischemia by improving angiogenesis, endothelial progenitor cell function and postnatal neovascularization. Atherosclerosis 229: 295-303. [Crossref]

32. Fernández JM, Rosado-Álvarez D, Da Silva Grigoletto ME, Rangel-Zúñiga OA, Landaeta-Díaz LL, et al. (2012) Moderate-to-high-intensity training and a hypocaloric Mediterranean diet enhance endothelial progenitor cells and fitness in subjects with the metabolic syndrome. Clin Sci (Lond) 123: 361-373. [Crossref]

33. Volaklis KA, Tokmakidis SP, Halle M (2013) Acute and chronic effects of exercise on circulating endothelial progenitor cells in healthy and diseased patients. Clin Res Cardiol 102: 249-257. [Crossref]

34. Kinaan M, Ding H, Triggle CR (2015) Metformin: An Old Drug for the Treatment of Diabetes but a New Drug for the Protection of the Endothelium. Med Princ Pract 24: 401-415. [Crossref]

35. Zeng G, Nystrom FH, Ravichandran LV, Cong LN, Kirby M, et al. (2000) Roles for insulin receptor, PI3-kinase, and Akt in insulin-signaling pathways related to production of nitric oxide in human vascular endothelial cells. Circulation 101: 15391545. [Crossref]

36. Erdogdu O, Nathanson D, Sjöholm A, Nyström T, Zhang Q (2010) Exendin-4 stimulate proliferation of human coronary artery endothelial cells through eNOS-, PKA- and PI3K/Akt-dependent pathways and requires GLP-1 receptor. Mol Cell Endocrinol 325 : 26-35. [Crossref]

37. Su JB (2015) Vascular endothelial dysfunction and pharmacological treatment. World J Cardiol 7: 719-741. [Crossref]

38. Christina L O’Neill, Michelle T O’Doherty, Sarah EJ Wilson, Amer A Rana, Claire E Hirst, et al. (2012) Therapeutic revascularisation of ischaemic tissue: the opportunitie and challenges for therapy using vascular stem/progenitor cells. Stem Cell Research and Therapy 3.

39. Cho HJ, Kim HS, Lee MM, Kim DH, Yang HJ, et al. (2003) Mobilized endothelia progenitor cells by granulocyte-macrophage colony-stimulating factor accelerate reendothelialization and reduce vascular inflammation after intravascular radiation. Circulation 108: 2918-2925. [Crossref]

40. Segal MS, Shah R, Afzal A, Perrault CM, Chang K, et al. (2005) Nitric oxide cytoskeletal-induced alterations reverse the endothelial progenitor cell migratory defect associated with diabetes. Diabetes 55: 102-109. [Crossref]

41. Cheang WS, Wong WT, Tian XY, Yang Q, Lee HK, et al. (2011) Endothelial nitric oxide synthase enhancer reduces oxidative stress and restores endothelial function in $\mathrm{db} / \mathrm{db}$ mice. Cardiovasc Res 92: 267-275. [Crossref]

42. Orea-Tejeda A, Balderas-Munoz K, Castillo-Martínez L, Infante-Vazquez O, Martinez Memije R, et al. (2013) Effect of ivabradine on endothelial function in diastolic and right heart failure patients. Cardiol Res Pract: 603913. [Crossref]

43. Natarajan V, Dudek SM, Jacobson JR, Moreno-Vinasco L, Huang LS, et al. (2013) Sphingosine-1-phosphate, FTY720, and sphingosine-1-phosphate receptors in the pathobiology of acute lung injury. Am J Respir Cell Mol Biol 49: 6-17. [Crossref]

Copyright: (C2016 Chirayath HH. This is an open-access article distributed under the terms of the Creative Commons Attribution License, which permits unrestricted use, distribution, and reproduction in any medium, provided the original author and source are credited. 